\title{
IMPLEMENTASI TEKNOLOGI DALAM PENGEMBANGAN MAKANAN RINGAN KARAK KALIANG KHAS KOTA SOLOK
}

\author{
Eka Candra Lina ${ }^{\left.1^{*}\right)}$, Caesar Welya Refdi ${ }^{2)}$, Prima Fithri ${ }^{3)}$, dan Wenny Surya Murtius ${ }^{2)}$, \\ 1) Fakultas Pertanian Universitas Andalas \\ ${ }^{2)}$ Fakultas Teknologi Pertanian Universitas Andalas \\ ${ }^{3)}$ Fakultas Teknik Universitas Andalas \\ *) Email: eka_candra@agr.unand.ac.id
}

\begin{abstract}
ABSTRAK
Inkubator bisnis memiliki peran sebagai lembaga pendamping yang membantu para pelaku usaha menjadi mandiri. Program pembinaan berjangka dihadirkan dalam bentuk training, coaching, mentoring, dan evaluating dengan tujuan mengurangi resiko kegagalan bisnis, memperoleh akses pasar, akses implementasi teknologi dan akses pendukung lainnya. Kegiatan inkubasi produk unggulan daerah merupakan kerjasama Unit Inkubator Bisnis Teknologi dibawah Science Techno Park (STP) Universitas Andalas dengan Kota Solok yang bertujuan melahirkan wirausaha mandiri yang menjadi cikal bakal klaster industri. Usaha Kecil Menengah (UKM) makanan ringan adalah salah satu jenis usaha yang menjadi fokus pengembangan. Kegiatan yang dilakukan dalam program inkubasi ini dilaksanakan dalam bentuk seminar sehari, workshop implementasi teknologi, pendampingan/inkubasi bisnis, kunjungan industri, Branding dan Packaging. Makanan ringan khas Kota Solok antara lain olahan singkong yang disebut Karak Kaliang dan aneka keripik dari berbagai jenis bahan baku, diantaranya keripik pare. Karak kaliang dari Kota Solok memiliki ciri khas yang tidak dimiliki daerah lain yang memproduksi makanan yang sama. Karak kaliang Kota Solok berwarna putih bersih, ukurannya lebih kecil dibandingkan karak kaliang dari daerah lain. Selama ini karak kaliang dan keripik pare di produksi secara tradisional yang memiliki beberapa kekurangan antara lain, biaya produksi cukup tinggi karena minyak yang digunakan untuk menggoreng hanya bisa digunakan 3 kali ulangan, produk tidak tahan di simpan lama karena mudah tengik, upah tenaga kerja tinggi, pemasaran di tingkat lokal saja. Setelah mendapat sentuhan inovasi muncullah karak kaliang yang di produksi secara lebih higienis, sehat dan kekinian dengan packaging dan branding baru, begitu juga dengan keripik pare. Kemajuan ini diharapkan dapat meningkatkan segmen pasar makanan ringan khas kota Solok, memperluas pemasaran, meningkatkan daya simpan dan daya saing produk. UKM mitra di harapkan mampu menjadi pioneer bagi kemajuan industri makanan ringan di kota Solok.
\end{abstract}

Kata kunci: inkubasi, industri, karak kaliang, makanan ringan, UKM

\section{Technology Implementation in The Development of Lightweight Food in Kaliang Special City, Solok City}

\begin{abstract}
The business incubator has a role as a companion institution that helps entrepreneurs become independent. Incubator programs are presented in training, coaching, mentoring, and evaluating to reduce the risk of business failure, gaining market access, access to technology implementation, and other supporting access. The incubation activity for superior regional products is a collaboration between the Technology Business Incubator Unit under the Andalas University Science Techno Park (STP) with the City of Solok, aiming to create independent entrepreneurs who become the forerunners of industrial clusters. Small and Medium Enterprises (UKM) snacks are one type of business that focuses on development. Activities carried out in this incubation program are carried out in one-day seminars, technology implementation workshops, business mentoring / incubation, industrial visits, branding, and packaging. Solok typical snacks include processed cassava called karak kaliang and various chips from various raw materials, including pare chips. karak kaliang from Solok City has characteristics that other regions that produce the same food don't have. Karak Kaliang from Solok City is pure white in color,
\end{abstract}


smaller in size than Karak Kaliang from other areas. There are several problems with snacks production, such as Cost production, product quality, high labor wages, the market consumer. After receiving a touch of innovation, Karak kaliang characters are produced in a more hygienic, healthier, and up-to-date manner with new packaging and branding, as well as the bitter melon chips. This program is expected to increase the typical snack market segment of Solok city, expand marketing, increase shelf-life, and product competitiveness. SME partners expected to become a pioneer for the advancement of the snack industry in Solok.

Keyword: incubation, industry, karak kaliang, snacks, SMEs

\section{PENDAHULUAN}

Inkubator bisnis oleh Canadian Business Incubator (CBI) didefinisikan sebagai konsep pemupukan wirausaha berkualifikasi dalam ruang kerja yang dikelola oleh suatu lembaga yang disebut inkubator (Adkins, 2011; NBIA, 2012). Inkubator mendukung bisnis berkualifikasi melalui kegiatan mentoring, pelatihan, jejaring profesi, dan membantu dalam mencarikan pendanaan hingga mereka lulus sesuai standar kelulusan yang telah ditentukan dan dapat bertahan dalam lingkungan bisnis atau mandiri.

Di Indonesia sendiri, sejarah inkubator bisnis sudah dirintis sejak 1993 yang dibentuk oleh perguruan-perguruan tinggi di Indonesia.. Salah satu perguruan tinggi yang memiliki inkubator bisnis adalah Universitas Andalas (Unand). Inkubator Bisnis Teknologi Unand merupakan unit yang berada di bawah Science Techno Park (STP), bekerja mendorong mahasiswa dan mitranya untuk tergabung di dalam inkubator bisnis. Mitra yang dimaksud salah satunya adalah UMKM.

Kerjasama STP Unand dengan Kota Solok telah dirintis melalui program inkubasi produk unggulan daerah. Posisi Kota Solok yang berada pada jalur lintas Sumatera menjadi keuntungan bagi UMKM di daerah tersebut karena sangat berpotensi dalam pengembangan bisnis atau usaha berskala industri. Makanan Ringan merupakan salah satu binis yang dapat dikembangkan karena bisa dijadikan sebagai bisnis oleh-oleh khas Kota Solok. Selain itu, di Kota Solok telah di bentuk Ikatan Pengusaha Makanan Ringan (IPMR) Kota Solok.

Pemerintah Kota Solok melalui Dinas Perdagangan dan Koperasi dan Usaha Kecil dan Menegah Kota Solok, melakukan pembinaan dan pemberdayaan dengan berbagai pelatihan dan fasilitasi bagi pengembangan UMKM menjadi Industri Kecil Menengah (IKM) khususnya IKM Makanan Ringan. Selanjutnya diharapkan akan terbentuk kluster industri makanan ringan di Kota Solok. Program yang di berikan tahun 2020 melibatkan STP Unand dan Inbistek Unand sebagai fasiltator. Bentuk fasilitasi Inkubator Teknologi dan Bisnis terhadap UKM makanan ringan di Kota Solok adalah dengan melakukan pendampingan/pembinaan (inkubasi) (Lina et al. 2019), transfer pengetahuan dan teknologi diharapkan dapat memberi kemajuan yang signifikan terhadap pelaku UMKM Kota Solok agar berkembang terarah di era disruptif (Kasali 2017). Mampu bersaing, mandiri, membentuk kluster industri dan berdampak bagi peningkatan perekonomian daerah. 


\section{Waktu dan Tempat}

\section{METODOLOGI}

Kegiatan ini dilaksanakan selama enam bulan, yaitu dari bulan April hingga September 2020. Kegiatan ini dilaksanakan di lokasi usaha mitra di Kota Solok, Science Techno Park Unand, dan Pilot Plant Universitas Andalas.

\section{Pelaksanaan Program}

Kegiatan inkubasi UMKM makanan ringan di Kota Solok ini dilaksanakan dalam bentuk beberapa kegiatan, diantaranya: Seminar sehari secara online, workshop implementasi teknologi, pendampingan inkubasi bisnis, studi banding, pelatihan branding dan packaging. Berdasarkan situasi yang telah dijelaskan, terlihat bahwa UMKM Kota Solok membutuhkan inkubasi bisnis produk makanan ringan guna memberikan sentuhan inovasi dan teknologi pada produk agar memiliki nilai jual yang lebih tinggi, segmentasi pasar yang lebih luas, meningkatkan daya simpan dll. Kegiatan yang dilakukan diantaranya:

1. Webinar

Kegiatan ini bertujuan untuk transfer ilmu pengetahuan kepada mitra mengenai makanan ringan. Kegiatan dilaksanakan secara online karena pandemik Covid-19.

\section{Workshop Implementasi Teknologi.}

Kegiatan ini bertujuan untuk memberikan wawasan dasar terhadap UKM terkait pentingnya penggunaan teknologi dalam pengembangan produk. Dalam kegiatan workshop ini, di hadirkan narasumber-narasumber yang ahli dalam bidang tersebut. Inovasi produk di perlukan dalam pengembangan bisnis selain itu penggunaan teknologi dapat mengelenggarakan bisnis secara efektif dan efisien.

\section{Pendampingan Inkubasi Bisnis}

Mitra dalam hal ini UMKM yang akan di inkubasi terlebih dahulu mengikuti beberapa tahapan yang telah disyaratkan diantaranya:

- Seleksi Tenant

Seleksi tenant dilakukan dengan menggunakan media online sebagai pendaftaran awal. Setelah didapatkannya calon tenant yang akan di seleksi, proses seleksi dilakukan dengan metode wawancara kepada tenant yang mendaftar dengan memberikan beberapa bentuk pertanyaan salah satunya tentang usaha bisnis yang ada.

- Visitasi Tenant

Visitasi dilakukan sebagai proses validasi untuk tenant yang akan dipilih. Metode yang dilakukan adalah observasi langsung ke lapangan dan metode checklist untuk indikator yang sesuai atau tidaknya dengan yang telah ditetapkan.

- Pendampingan Tenant

Pendampingan tenant merupakan kegiatan terakhir dari proses pemilihan tenant. Pendampingan dilakukan untuk tenant yang terpilih yang akan mendapat training, coaching, dan mentoring bisnis. 
- Workshop implementasi teknologi

Worshop penggunaan teknologi yang tepat dalam pengembangan produk makanan ringan ini meliputi penggunaan vacuum frying dan penambahan pewarna alami ke dalam produk. vacuum frying yaitu alat yang digunakan dalam proses penggorengan tanpa mengubah rasa, aroma dan warna. Penggorengan vakum dilakukan dalam ruang tertutup dengan kondisi tekanan rendah sekitar $70 \mathrm{cmHg}$. Dengan penurunan tekanan maka suhu penggorengan bisa dilakukan relatif lebih rendah dibandingkan suhu penggorengan dengan tekanan atmosfir.

Prinsip utama cara kerja alat ini adalah melakukan penggorengan pada kondisi vakum, $7.52 \mathrm{cmHg}-7.6 \mathrm{cmHg}$. Kondisi vakum ini dapat menyebabkan penurunan titik didih minyak dari $110^{\circ} \mathrm{C}-200^{\circ} \mathrm{C}$ menjadi $80^{\circ} \mathrm{C}-100^{\circ} \mathrm{C}$ yang dapat mencegah terjadinya perubahan rasa, aroma, dan warna. Penambahan warna yang digunakan adalah warna biru dari spirulina, warna ungu dari senduduk, warna hijau dari daun katuk.

4. Studi Banding

Bertujuan untuk melakukan kunjungan ke UMKM yang sudah lebih maju, mempelajari tata kelola bisnis, dan berbagi pengalaman.

5. Branding dan Packaging

Selanjutnya, hal yang mendukung dalam pengembangan produk adalah adanya inovasi terhadap branding dan packaging yang dapat menarik perhatian konsumen. Branding dan packaging mempunyai nilai tersendiri dalam proses promosi makanan. Semakin menarik packaging dan kuat brandingnya, semakin tinggi rasa keingintahuan konsumen terhadap produk tersebut, sehingga untuk memecahkan rasa keingintahuannya, konsumen akan membeli produk tersebut.

\section{HASIL DAN PEMBAHASAN}

Berdasarkan kegiatan yang telah dilakukan, terlihat adanya keinginan mitra untuk mengembangkan produk mereka menjadi produk yang lebih berinovasi. Terlihat dari antusiasnya peserta dalam mengikuti webinar yang dibuka untuk umum tersebut. Banyak peserta yang ingin mengetahui lebih lanjut lagi tentang pentingnya teknologi dalam pengembangan produk dan bagaimana cara yang dapat dilakukan. Saat ini, dunia bisnis terutama bidang makanan, sangat banyak diminati. Oleh sebab itu, banyak terjadi persaingan antar pebisnis. Dan untuk bisa mengalahkan produk saingan, tentu produk harus memiliki kebaharuan yang mampu menarik hati konsumen dan berbeda dengan produk-produk yang ada.

Dengan adanya inkubasi bisnis ini, tenant yang telah terpilih akan didampingi dalam kegiatan pengembangan produk. Saat ini, teknologi yang ingin di transfer ke tenant adalah teknologi vacum frying dan penggunaan pewarna alami pada makanan ringan. Menurut Muchtadi (2008) berdasarkan kondisi prosesnya, penggorengan dapat dilakukan pada kondisi tekanan atmosferik, bertekanan lebih tinggi dari tekanan atmosfer, dan pada kondisi vakum. Penggorengan pada kondisi tekanan atmosfer terjadi pada penggorengan konvensional dimana proses penggorengan dilakukan secara 
terbuka pada tekanan normal atmosfer. Suhu proses penggorengan pada tekanan atmosfer terjadi pada suhu titik didih minyak yaitu sekitar 180-200 ${ }^{0} \mathrm{C}$.

Proses penggorengan pada kondisi vakum adalah proses yang terjadi pada tekanan lebih rendah dari tekanan atmosfer, hingga tekanan lebih kecil dari 0 atau kondisi hampa udara. Proses penggorengan pada tekanan yang lebih rendah akan menyebabkan titik didih minyak goreng juga lebih rendah, misalnya dapat mencapai 90 ${ }^{0} \mathrm{C}$. Proses penggorengan yang terjadi pada suhu yang rendah ini menyebabkan proses ini sangat sesuai digunakan untuk menggoreng bahan pangan yang tidak tahan suhu tinggi. Bahan pangan seperti sayuran dan buah segar, apabila digoreng pada tekanan atmosfer akan segera mengalami kecoklatan dan gosong, teksturnya juga lembek dan liat karena tidak banyak melepaskan air yang dikandungnya. Sedangkan bila digoreng dengan kondisi vakum, suhu penggorengan akan lebih rendah sehingga dapat dihasilkan warna hasil gorengan yang baik, serta tekstur yang renyah.
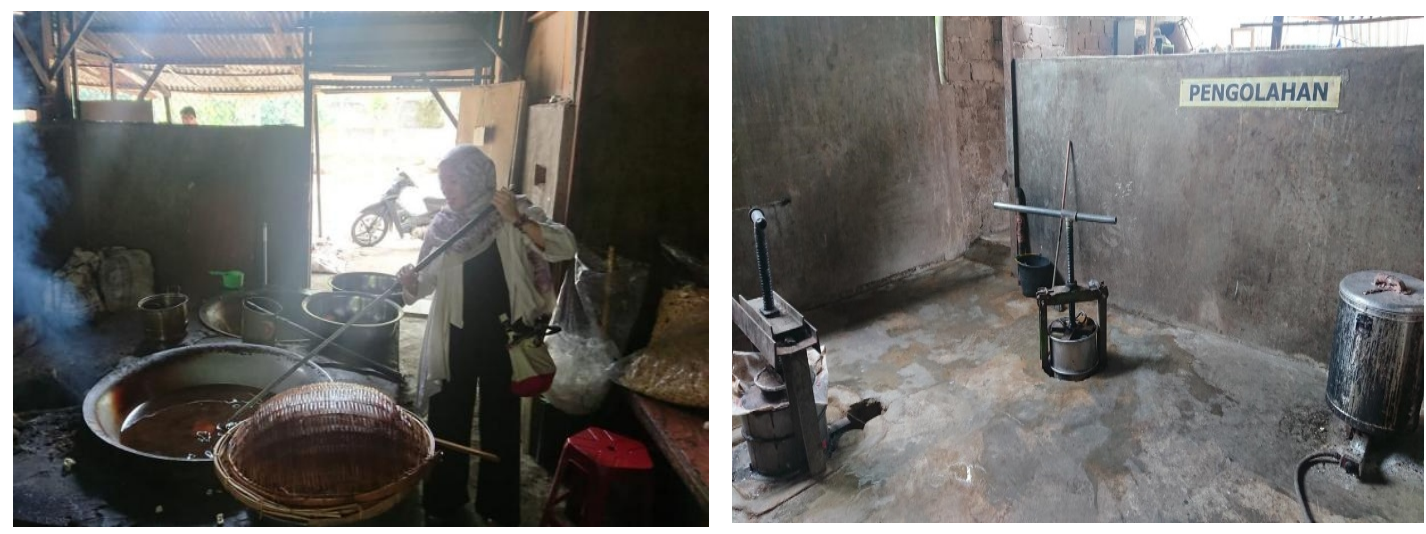

Gambar 1. Pengolahan Makanan Ringan Karak Kaliang secara Tradisional

Pada Gambar 1 dan 2, terlihat jelas perbedaan sistem penggorengan secara tradisional dan menggunakan vacuum frying. Sistem tradisional membutuhkan banyak tenaga kerja selalu diaduk agar tidak gosong, biaya bahan baku seperti minyak goreng lebih tinggi dikarenakan minyak hanya bisa di pakai 3 kali saja (hitam). Jika menggunakan teknologi vacuum frying, kita tidak membutuhkan banyak minyak goreng dan tenaga kerja, karena dengan teknologi ini, makanan akan masak dengan sendirinya sesuai dengan pengaturan yang telah diatur secara otomatis akan matang dengan sendirinya tanpa mengubah aroma, warna dan rasa. Selain itu, dengan penggunaan vacum frying ini, dapat menghemat minyak yang digunakan, dapat di pakai berulang hingga 30 kali.

Transfer pengetahuan mengenai pewarna alami juga dilakukan pada saat workshop. Marpaung (2018) menyebutkan bahwa pewarna alami dari tumbuhan lokal Indonesia sangat potensial untuk dikembangkan. Kesadaran masyarakat akan makanan sehat semakin tinggi, kebutuhan bahan-bahan alami pengganti bahan sintetis semakin tinggi diantaranya pewarna makanan. 
Website. http://hilirisasi.lppm.unand.ac.id
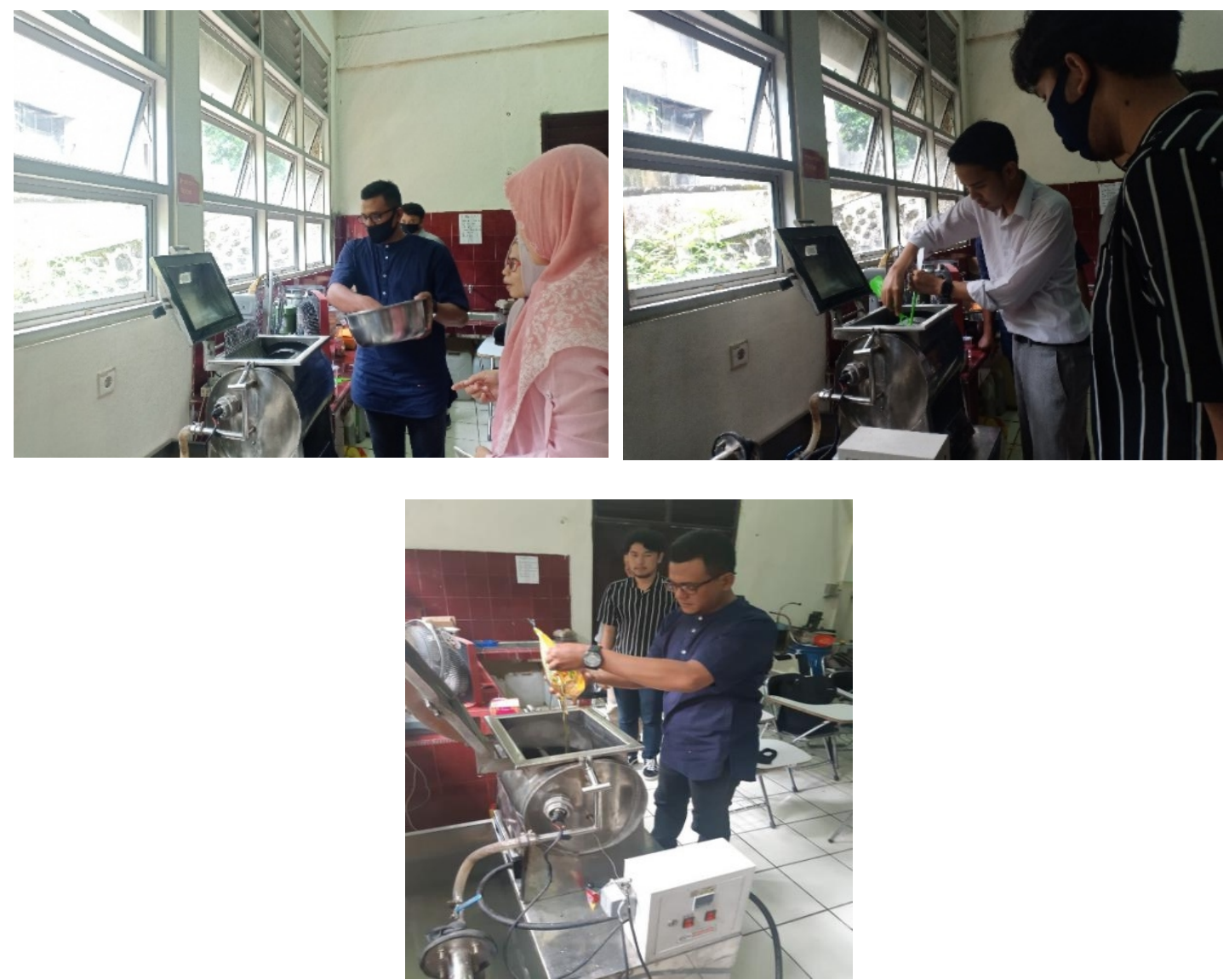

Gambar 2. Pengolahan Makanan Ringan Karak Kaliang dengan Menggunakan Alat Vakum Frying
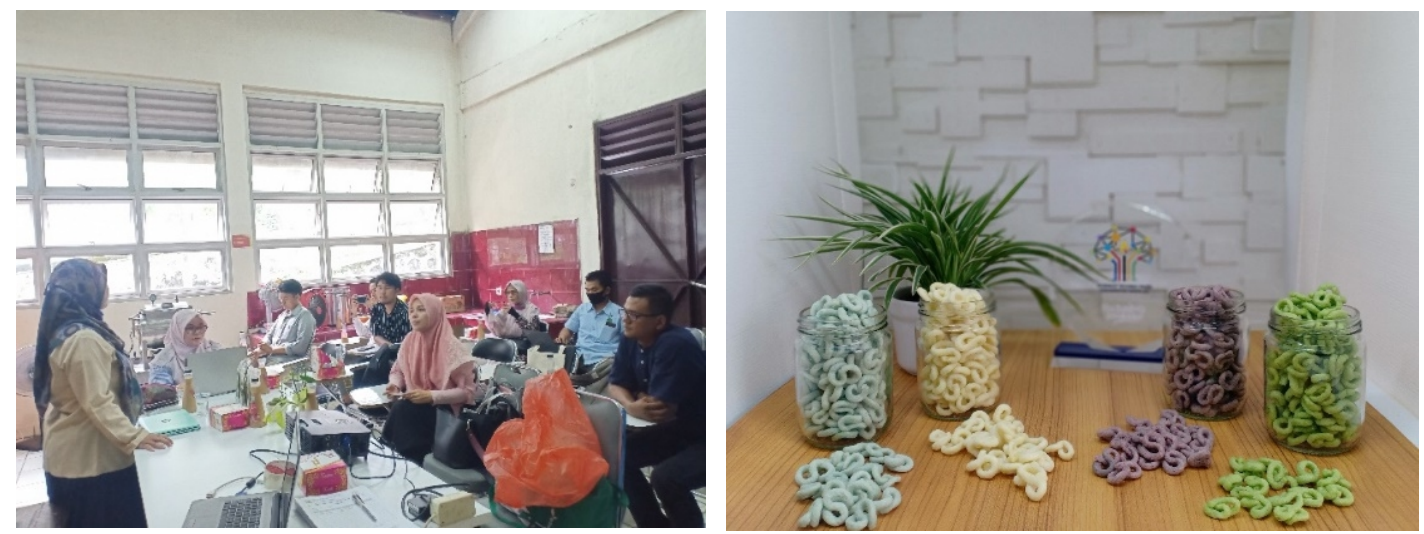

Gambar 3. Diskusi Penggunaan Pewarna Alami Pada Produk Makanan, Biru (Spirulina), Ungu (Senduduk), Hijau (Katuk), Putih (Original).

Tahapan selanjutnya setelah prototype berhasil di buat adalah strategi branding dan packaging yang menarik. Kekuatan branding dan packaging akan berpengaruh terhadap pengembangan segmen pasar dan harga jual produk. Produk makanan ringan yang di produksi dengan teknologi vacuum frying dan sentuhan pewarna alami serta 
pengeringan dengan spinner memiliki keunggulan yaitu lebih sehat, lebih renyah, lebih tahan lama, dan lebih menarik dibandingkan dengan produk sebelumnya yang di produksi secara tradisional. Keunggulan ini dapat membidik segmentasi pasar milenial dan menengah ke atas. Pengemasan yang lebih modern dibantu dengan designer dari Cimahi Techno Park menjadikannya menarik seperti pada Gambar 4.

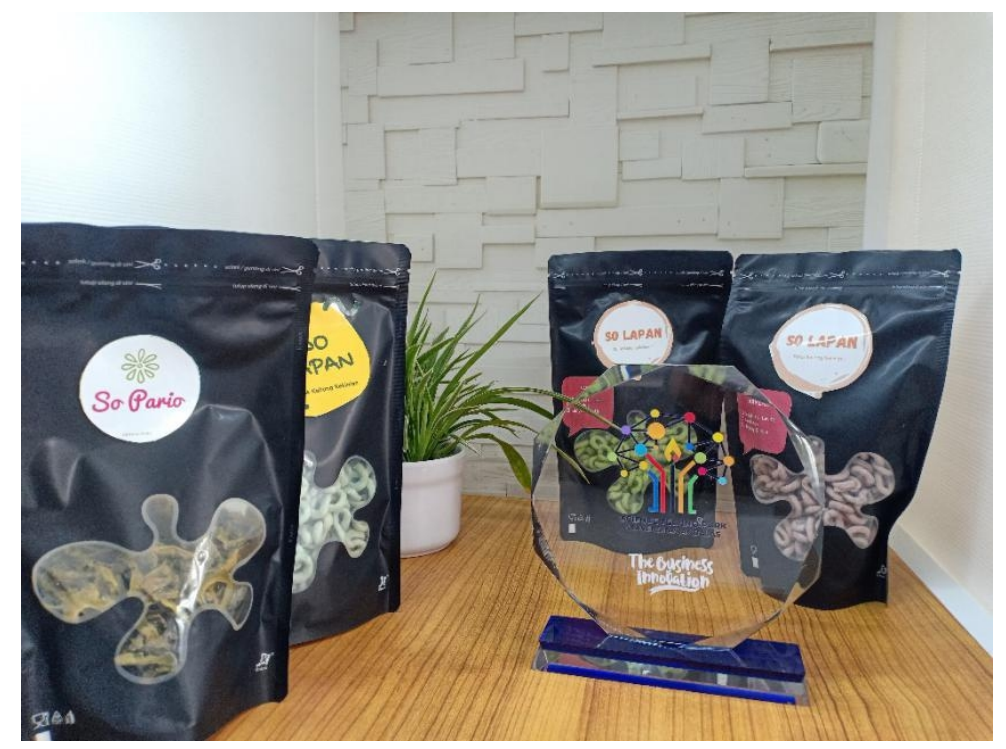

Gambar 4. Karak Kaling Kemasan Baru dan Brand Baru

\section{KESIMPULAN DAN SARAN}

Sinergi pemerintah dengan sumber inovasi dalam hal ini perguruan tinggi sangat mempengaruhi keberhasilan mitra binaan/tenant. Implementasi teknologi yang dimiliki perguruan tinggi kepada mitra atau pengguna untuk pengembangan bisnis berdampak positif bagi keberlanjutan usaha dan daya saing agar dapat bertahan di era disruptif. Penggunaan teknologi vacuum frying dapat meningkatkan kualitas produk, kuantitas produksi, daya saing produk dan mengurangi cost produksi. Penggunaan warna alami pada makanan dapat memberi warna menarik dan meningkatkan kepercayaan konsumen pada produk berlabel sehat dan halal.

\section{UCAPAN TERIMAKSIH}

Penulis mengucapkan terima kasih kepada Science Techno Park Unand yang bekerja sama dengan pemerintah Kota Solok untuk terselenggaranya inkubasi produk makanan ringan khas Kota Solok. Ucapan terima kasih juga disampaikan kepada masyarakat UMKM yang berada di Kota Solok, Dinas Perdagangan Koperasi dan Usaha Kecil Menengah Kota Solok serta tim teknis atas bantuan dalam kegiatan ini. 


\section{DAFTAR PUSTAKA}

Adkins, D. 2011. How business incubators have adapted accelerator-like services to woo new clients and serve more entrepreneurs. NBIA Quick References.

Barlina, R., \& Barlina, R. B. P. T. K. dan P. L. 2016. Potensi Buah Kelapa Muda Untuk Kesehatan dan Pengolahannyar Perspektif. https://doi.org/10.21082/p.v3n2.2004.46-60.

Kasali R. 2017. Disruption. PT. Gramedia Pustaka Utama, Jakarta. 495 hal.

Lina EC, Games D, Fithri P, Leony Y. 2019. Inkubasi Produk Unggulan Nagari Sinuruik Kecamatan Talamau, Kabupaten Pasaman Barat. Jurnal Nagari Membangun, 2 (3b): 288-295.

Marpaung AM. 2018. Potensi Pewarna Alami Lokal untuk Industri Pangan. Food Review Indonesia 13(9): 6 hal

NBIA. (2012). FAQs about business incubation. How many business incubators are there? NBIA - National Business Incubators Association, USA.

Sartika, R. A. D. (2010). Pengaruh Suhu Dan Lama Proses Menggoreng (Deep Frying) Terhadap Pembentukan Asam Lemak Trans. MAKARA of Science Series. https://doi.org/10.7454/mss.v13i1.354 